\title{
Postural Balance in the Elderly with Mild Cognitive Impairment: Relationship to Accidental Falls
}

\author{
Josélia Braz dos Santos Ferreira', Selma Petra Chaves Sá ${ }^{2}$, Rosimere Ferreira Santana ${ }^{2}$, \\ Ana Maria Domingos ${ }^{3}$, Juliana Peres da Costa Pereira ${ }^{4}$, Luciana Krauss Rezende 5 \\ ${ }^{1}$ The AntônioPedro Hospital/UFF/Niterói, The Miguel Pedro Municipal Hospital of Geriatrics and Gerontology \\ (SMS), Rio de Janeiro, Brazil \\ ${ }^{2}$ The Aurora Afonso Costa Nursing School, Fluminense Federal University (UFF), Niterói, Brazil \\ ${ }^{3}$ The AnaNeri Nursing School, Federal University of Rio de Janeiro/UFRJ, Rio de Janeiro, Brazil \\ ${ }^{4}$ The Estacio de Sa University, The Redentor College, Rio de Janeiro, Brazil \\ ${ }^{5}$ The Aurora Afonso Costa Nursing School (UFF), Niterói, Brazil \\ Email: joseliabraz42@yahoo.com.br, spetra@ig.com.br, rosifesa@gmail.com, \\ anamaria_domingos@yahoo.com.br,perezjuju@hotmail.com, lukrare@uol.com.br
}

Received 18 January 2016; accepted 22 March 2016; published 25 March 2016

Copyright (C) 2016 by authors and Scientific Research Publishing Inc.

This work is licensed under the Creative Commons Attribution International License (CC BY). http://creativecommons.org/licenses/by/4.0/

(c) (i) Open Access

\begin{abstract}
This study analyzed postural balance in the elderly with mild cognitive impairment and its relationship to accidental falls. A quantitative and quasi-experimental method was used in a sample of 43 elderlies between 64 and 88 years old, mostly females. Data collection was performed in two Basic Health Units in the city of Rio de Janeiro in 2014. The instruments used were the Mini-Mental State Examination (MMSE), Tinetti scale, Motor Scale for the Elderly (EMTI) scale, and Elderly Falls Diary. The data were analyzed with the SAS statistical software version 9.3.1. The scales were applied before and after the psychomotor interventions. A significant difference was observed between the evaluating moments. Balance improvements were observed in all age groups, suggesting that all elderlies, regardless of age, showed satisfactory responses to the implemented psychomotor activities. The elderlies who fell more frequently were those between 60 and 69 years old. It is noteworthy that the age group with the lowest incidence of falls was that of elderlies between 70 and 79 years old. It was concluded that psychomotor activities are beneficial, regardless of age, proving their effectiveness when continued stimuli with cognitive and psychomotor activities are carried out.
\end{abstract}

Note for the authors: Josélia Braz dos Santos Ferreira: Master’s degree in Science in Health Care, RN; Selma Petra Chaves Sá, Rosimere Ferreira Santana: PhD in Nursing, Full Professor; Ana Maria Domingos: PhD in Nursing, Associate Professor; Juliana Peres da Costa Pereira RN, Specialist in Cardiology; Luciana Krauss Rezende: Physiotherapist, PhD in Developmental Disorders, PhD in Health Care Sciences. 
Keywords

Postural Balance, Accidental Falls, Elderlies, Mild Cognitive Impairment

\section{Introduction}

Working with the elderly is a challenge in many ways. It brings the need for improved knowledge of geriatrics and gerontology in a multi-professional team, because old age is a period characterized by two aspects: it can be normal (senescence) or marked by conditions that impair individual functioning in daily activities (senility). Senescence is considered a healthy aging process in which all cognitive functions are preserved. Normal aging, in this case, can be categorized as satisfactory (success) or common (with losses, but with the capacity to improve functional losses). Senility occurs when these damages or losses occur with greater intensity, with a marked functional disability that leads to possible changes in the nervous system, causing cognitive impairment [1].

The Mild Cognitive Impairment (MCI) refers to elders who show some degree of cognitive impairment, when compared to normal people of the same age, but do not meet the criteria for dementia

Some of the clinical manifestations that affect the elderly with MCI are memory alterations and loss of balance and falls, which can compromise the quality of life of the elders affecting their autonomy and restricting functionality in daily activities.

Mild Cognitive Impairment (MCI) was proposed to refer to non-demented individuals-i.e., people with mild cognitive impairment. The criteria for the diagnosis of Mild Cognitive Impairment (MCI) are memory changes indicated by a slight downgrade in test scores, such as in the Mini-Mental State Examination-MMSE with a score of at least 24 points (performance with approximately 1.5 standard deviation points below the average of normal controls of same age and education level); however, with sustained general normal cognitive functions and socio-occupational activities [2] [3].

Cortex neuronal loss in the precentral gyrus and cerebellum occurs during aging. It is assumed that these alterations lead to a decrease in the overall praxis, which is related to the information-carrying areas that lead to loss of balance in elderlies. This loss of balance is affected by a reduction in neural activity that can compromise posture maintenance. The balance system is responsible for controlling body sway, and this mechanism declines with advancing age to a greater or lesser degree, depending on associations with other diseases or sedentary lifestyle, and can consequently lead to falls [4].

Studies report that the damage caused by falls reaches about $30 \%$ to $50 \%$ of cases, with $6 \%$ to $44 \%$ of these patients suffering serious damage such as fractures, subdural hematomas, and bleeding that can lead to death [5]. A fall can have a negative impact on the patient's mobility; as well it can generate anxiety, depression, and fear of falling again, which ultimately increases the risk of a new fall [6]. Thus, autonomy and functional capacity, which are understood as abilities of the elderly to take care of oneself [7], are important aspects to be analyzed in determining the risk of falls.

A fall is highlighted as a multifactorial event; thus, it is essential to emphasize the implementation of measures that include patient's risk assessment by a multi-professional care team and prevention of recurrent falls by defining safe environmental features, habits, and attitudes that may pose a risk [8].

It is fundamental that the nurse who cares for elderly people, especially those with MCI, knows how to evaluate balance and set care targets to minimize the risk of falls by analyzing and implementing interventions aiming at increased safety. The objective of this study was to analyze balance in the elderly with mild cognitive impairment and identify its relationship with the accidental falls.

\section{Methods}

This was a quantitative and quasi-experimental type of study conducted during four months with 43 elderlies aged 60 and older, of both genders, and users of two Basic Health Units (BHU) located in Niterói/RJ (Institution I) and Rio de Janeiro (Institution II). The study was conducted in the Geronto Geriatric Nursing Program of these institutions, where these individuals participated in Cognitive Workshops.

The evaluated elderlies presented mild cognitive impairment, which was surveyed in their medical records by the researcher. In addition, the establishment of a mild cognitive impairment status considered reports of tests that pointed to this stage of the disease, such as MRI, CT scan of the skull, and laboratory tests, among others. 
Referrals to geriatric assessment in the institutions involved were also considered.

The inclusion criteria were: individuals of both genders, aged 60 years and older, afflicted with Mild Cognitive Impairment (MCI), and with scores greater than 24 points in the Mini-Mental State Examination (MMSE) for individuals with higher education, or less than 18 points for individuals with high school equivalent education, or greater than 14 points for illiterates.

The exclusion criteria included individuals who:missed $25 \%$ of the psychomotor stimulation activities; presented severe deficit of vision; had recent bone injuries; were carriers of prosthetic joints in the lower limbs; were submitted to any surgical procedure in the last 6 months; were affected with labyrinthitis; and presented hemodynamically unstable cardiovascular disease.

A total of 56 elderlies were evaluated: 22 from Institution I and 34 from Institution II. The inclusion and exclusion criteria were applied to this group. Out of the 22 elderly patients evaluated from Institution I, only one (4.5\%) was excluded, due to a fall during data collection. Therefore, 21 participants from Institution I were included in the study outcomes, totaling $95.5 \%$ of those previously selected, which according to a survey conducted earlier in the study, was considered a significant sample size.

A total of 34 elderlies from Institution II were evaluated. Twelve elderlies were excluded (35.3\%) and 22 subjects, $64.7 \%$, were included in the study outcomes, which was also considered a significant sample number based on an initial study survey. Therefore, a total of 43 elderlies participated in the study.

The instruments used were: the Mini-Mental State Examination (MMSE) [9] [10]; Tinetti scale [11]; the Balance Motor Scale for the Elderly parameter (EMTI) [12]; and the Elderly Falls Diary [13].

Psychomotor activities were elaborated after the application of the scales to promote balance and functional capacity in the studied elderlies. Group activities were held for ten sessions, one per week in the two institutions. The Tinetti [11] and EMTI [12] scales were applied to the two evaluations: at the study's baseline and the end of the implemented psychomotor stimulation activities.

The Mini-Mental State Examination [9] [10] instrument was used only in the first evaluation aiming at evaluating the cognitive function of participants. This instrument was developed by Folstein and McHugh [9] and translated by Bertolucci et al. [10]; it consists of 11 items grouped into seven categories, planned to assess specific cognitive functions such as: time orientation (5 points), location orientation (5 points), three-word record (3 points), attention and calculation (5 points), recall of three words (3 points), language (8 points), and visual-constructive capacity ( 1 point). The score range is from zero to 30 . The validated version using the following cutoff points was employed in this study: 13 for illiterates, 18 for medium and low education level, and 26 for higher education level [10].

The Elderly Fall Diary [13] was used to record the occurrence of falls, which is a practical instrument with six items: date of the fall, place (living room, kitchen, bedroom, bathroom, backyard, street, or other), time, circumstances (tripping (T), slipping (E), imbalance (D), and others), fractures (Yes (Y)/No (N)), and if medical attention was needed (Yes $(\mathrm{Y}) / \mathrm{No}(\mathrm{N}))$. This instrument is for an individual use including space for subsequent notes. This instrument features the purpose of detecting the real reasons for falls in the studied population and was used throughout the study.

The instruments used to assess balance in the two evaluating moments (i.e., before and after the intervention) were the Tinetti [11] and Balance-EMTI [12] scales.

The validated version of the Tinetti scale, which is an instrument developed through the Mary Tinetti protocol [11] to detect alterations in locomotion and to diagnose and quantify the severity of impairment, can predict the risk of falls. According to this instrument, the lower the score, the greater the problem. Scores that are lower than 19indicate five times greater risk of fall. Therefore, individuals with scores below 19 are at high risk for falls; between 19 and 24,at moderate risk; and over 24, not at risk.

The Tinetti index comprises two scales: balance and gait. The balance score goes up to 16 points, and the gait score to 12 points, with a total index of 28 points. The balance evaluation contains ineitems: balance when seated, rising from a chair, attempting to rise, balance immediately after rising (first 5 seconds), standing balance, the three-time test, eyes closed, balance while turning 360 degrees, and balance while sitting. The gait evaluation contains seven items: gait start, length and height of steps, steps symmetry, steps continuity, direction, trunk, and ankles distance. In maneuvering tasks in which the use of a chair is needed, the patient initiates the evaluation in a rigid chair without armrests and with upright back [11].

The Motor Scale for the Elderly (EMTI) is an innovative and validated instrument [12] that enables new opportunities for the assessment and intervention in the elderly population. The evaluation through motor tests allows verifying the progressive stages of physical function in order to detect declines in physical parameters and 
plan effective strategies for intervention. Thus, we used the Balance EMTI motor parameter in this study because it is an explorative method that evaluates specific areas of human motricity (proprioception and stability of body movements).

Each test has different degrees of difficulties that are presented in a progressive increasing order. The results of the obtained scores in the evaluation allow the classification of motor parameters in levels, namely:very high (130 or more), high (120 - 129), normal high (110 - 119), normal medium (90 - 109), normal low (80 - 89), low (70 - 79), and very low (<70) [12]. In this study, balance was the only topic approached in this scale.

Implementation of interventions: the elderly could miss about $25 \%$ of the activities; that is, they could only miss two out of 10 sessions.

Exercise Program: after the application of scales, cognitive and psychomotor stimulation activities were prepared to improve the psychomotor quality, which was followed up by the researcher. The dynamics suggested by Rosa Neto were used [14]; music and videos taken from the Internet were added to the program according to each theme.

The SAS version 9.3.1statistical software was used for data analysis. A descriptive analysis of the data was carried out first considering the two evaluated occasions-before and after the implementation of psychomotor activities.

It is noteworthy that the study did not aim to compare the two institutions, but to compare the relationship between the presence of mild cognitive impairment and the risk of falls in the studied elderlies before and after the implementation of psychomotor activities in both institutions. Therefore, data from the two research institutions were evaluated together at the first and second evaluations.

The Shapiro-Wilks normality test was conducted; because the variables presented non-normal distribution, the nonparametric signal test was applied. The Kruskal-Wallis test with a 0.05 significance level was used to verify differences between measurements. A significant difference with 95\% confidence was observed between scores obtained in the first and second evaluations using the Tinetti [11] and Balance-EMTI [12] scales.

The study was approved in 2014 by the Ethics Committee for Research on Human Subjects from the Medical School of the Fluminense Federal University/FM/UFF/HUAP under number 531807. The ethical principles of voluntary and informed participation were respected.

\section{Results and Discussion}

A total of 37 elderlies (86.05\%) participated in the study; 31 women and six men (13.95\%). In this study, as in other studies with the elderly population, females are usually found in greater numbers than males. The IBGE data [15] confirm the predominance of females through census data showing 95.9 men for every 100 women. Therefore, there are 3.9 million more women than men in Brazil.

The age distribution was: 24 participants (55.81\%) aged between 70 and 79 years, 10 participants (23.26\%) aged between 80 and 89 years, and 9 participants aged (20.93\%) between 60 and 69 years. The average age was 74.95 years, with theminimumat64 and maximum at88 years.

Table 1 shows that 15 elderlies (34.88\%) presented scores between 15 and 23, which according to the MEEM scale is equivalent to suggestive signs of cognitive impairment; education in this group ranged from illiterate to four (4) incomplete school grades. Fifteen individuals (34.88\%) showed scores between 24 and 26 points, which indicates no alterations that are suggestive of cognitive impairment; and 13 individuals (30.24\%) showed scores between 27 and 30 points, which is indicative of preserved cognitive functions. The Mini-Mental State Examination (MMSE) scale averaged 24.41 points with a standard deviation of 3.45 points, within a range between 15 and 30 points.

Table 1. Distribution of elderlies according to their scores in the MEEM instrument at Institution Iin Niteróiand Institution II in Rio de Janeiro, 2014.

\begin{tabular}{cccc}
\hline & Scores & $\boldsymbol{n}$ & Education \\
\hline & Suggestive of cognitive deficit (23 points or less) & 15 & Illiterate to 4 incomplete years of education \\
MEEM & $\begin{array}{l}\text { Questionable or alterations not } \\
\text { suggestive of deficit (24 - 26 points) }\end{array}$ & 15 & 4 to 8 incomplete years of education \\
& Preserved cognitive functions (27 - 30 points) & 13 & 4 to 8 completed years of education \\
\hline
\end{tabular}

Source: Data from the study. 
There was a wide point variation in both institutions. Knowing that the cutoff point for dementia is influenced mainly by the level of education and age, [10] [16] a low cutoff point was established in this study due to the prevalence of illiteracy and low education. All elderlies were referred to participate in the study because they had been referred to participate in the cognitive workshop by geriatricians due to complaints of memory deficit.

The elderlies who presented low scores showed concern about developing a dementing process, and four of them (9.30\%) reported cases of dementia in the family. Two elderly women (4.65\%) wept because they could not remember the three words asked in the test. These participants were told about the benefits of an early diagnosis, as discussed in the study, and the importance of participating in cognitive and motor stimulation activities.

Table 2 shows the results after performing the Shapiro-Wilks normality test on the data to decide which would be the best statistical test to be used. Because no variable showed a normal distribution, the nonparametric signal test was applied. Through the equality test with 95\% confidence interval and 0.05 significance, it was observed that all variables showed differences; that is, there is a difference in the results from the first and second evaluation steps.

Table 3 shows the results of the two measurements performed on the Tinetti [10] and Balance EMTI [12] scales. The application of the Tinetti Scale [10], which evaluates balance and gait, revealed that 33 elderlies (76.74\%) showed some balance and gait deficits. Even more significant scores were observed in the second evaluation conducted, because there were 22 elderlies (51.16\%) in the first evaluation, with an average of 17.22 points and standard deviation of 1.23 points, corresponding to high risk for falls.

In the second evaluation and after participating in psychomotor activities, this number was reduced to five elderlies (11.62\%). This result is reflected in the classification of moderate risk for falls, which showed 11 elderlies (25.58\%) with an average of 21.45 points and standard deviation of 1.29 points in the first evaluation, and 28 elderlies (65.11\%) presenting moderate risk for falls with scores between 19 and 24, with an average of 20.67 points and 0.94 standard deviation in the second evaluation. Only five elderlies (11.62\%) were at a high risk for falls, showing scores lower than 19 and an average of 18 points.

Thus, the results from the second evaluation show that 17 elderlies (39.53\%) presented improved balance and gait and moved from the category of high risk for falls to that of moderate risk. However, according to the scale, ten elderlies (23.26\%) showed no risk for falls in the second evaluation. The average of these ten elderlies was 26.4 points with a standard deviation of 1.42 points in the first evaluation, and 27 points with a standard deviation of 1.76in the second evaluation. The $p$-value was 0.0001 in both averages. The increased number of elderlies in the moderate risk category indicated a positive factor in the improvement in balance and gait.

The results from the Balance EMTI scale showed an average of 79.81 points in the first evaluation, which was equivalent to the low classification. The results from the second evaluation showed an average of 92.37 points, corresponding to the normal medium classification, with a standard deviation of 16.72 points and $p$-value of 0.0001 .

The results with the best scores in the second evaluation in both scales met the expectations of this study because the balance in the EMTI scale changed to the normal medium classification with an average of 92.37 points. In the Tinetti Scale, only five elderlies (11.63\%) remained at high risk for falls and 28 (65.11\%) were at moderate risk for falls, averaging 20.67 points.

Therefore, in the second evaluation, we obtained results from the application of the Tinetti and EMTI scales in which we could evaluate the effectiveness of psychomotor activities. The term psychomotricity first emerged with Dupré in 1920 representing an interlacement between movement and thought. Since 1909, he already drew the attention of his students to motor imbalance, calling it "motor weakness." He observed that there was a close relationship between psychological and motor anomalies, which led him to formulate the term psychomotricity [17].

The movements considered most difficult for the elderly are those of body dissociation, lateral dominion, coordination of upper and lower limbs, speed, agility, breath, proprioception, rhythm, and body memory. Such

Table 2. Normality and equality tests on the averages of the studied variables. Rio de Janeiro, 2014.

\begin{tabular}{ccc}
\hline Variable & Normality Test & Average equality test \\
\hline Balance and Gait-Tinetti & 0.0001 & 0.0001 \\
Balance-EMTI & 0.0015 & 0.0001 \\
\hline
\end{tabular}

Source: Data from the study. 
Table 3. Distribution of elderlies according to risk for fall and classification in the first and second evaluations. Niteróiand Rio de Janeiro, 2014.

\begin{tabular}{|c|c|c|c|c|}
\hline Variables in the First Evaluation & $n$ & $\%$ & Average & \\
\hline \multicolumn{5}{|l|}{ Risk for Fall (E. Tinetti) } \\
\hline High risk (Less than 19) & 22 & 51.16 & 17.22 & \\
\hline Moderaterisk (19 - 24) & 11 & 25.58 & 21.45 & \\
\hline No risk (Over 24) & 10 & 23.26 & 26.4 & \\
\hline Total & 43 & 100 & 20.44 & \\
\hline \multicolumn{5}{|l|}{ Classification } \\
\hline \multicolumn{5}{|l|}{ Balance-EMTI } \\
\hline Verylow $(<69)$ & 14 & 32.56 & & \\
\hline Low (70 - 79) & 10 & 23.25 & & 1 \\
\hline Normal low (80 - 89) & 5 & 11.63 & & . \\
\hline Normal medium (90 - 109) & 10 & 23.25 & 79.81 & 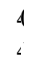 \\
\hline Normal high (110-119) & 2 & 4.65 & & \\
\hline High (120 - 129) & 1 & 2.33 & & \\
\hline Very high (>130) & 1 & 2.33 & & \\
\hline Variables in the Second Evaluation & $n$ & $\%$ & Average & t. \\
\hline \multicolumn{5}{|l|}{ Risk for Fall (E. Tinetti) } \\
\hline High risk (Less than 19) & 5 & 11.62 & 18 & 1 \\
\hline Moderaterisk (19 - 24) & 28 & 65.11 & 20.67 & $\|$ \\
\hline No risk (Over 24) & 10 & 23.26 & 27 & \\
\hline Total & 43 & 100 & 21.83 & : \\
\hline \multicolumn{5}{|l|}{ Classification } \\
\hline \multicolumn{5}{|l|}{ Balance-EMTI } \\
\hline Verylow $(<69)$ & 0 & 0 & & \\
\hline Low (70 - 79) & 13 & 30.23 & & \\
\hline Normal low (80 - 89) & 9 & 20.93 & & \\
\hline Normal medium (90 - 109) & 13 & 30.23 & 92.37 & $\begin{array}{l}1 \\
1\end{array}$ \\
\hline Normal high (110-119) & 3 & 6.97 & & \\
\hline High (120 - 129) & 3 & 6.97 & & \\
\hline Very high (>130) & 2 & 4.65 & & \\
\hline
\end{tabular}

Caption: n: frequency, \%: percentage, SD: Standard Deviation. Source: Data from the study.

movements are associated primarily with the natural aging process, as well as physical exercise, motivation, and quality of life. Motor skills contribute to their independence in daily life and social adaptation. The elderly who present his full potential to move and discover the world is usually happy and a well adapted individual [14].

Table 4 shows the evaluation of Balance and Gait in the Tinetti scale in participants aged between 60 and 69 years, 70 and 79, and 80 and 89 years with assigned average scores obtained before and after the implementation of psychomotor activities. The Kruskal-Wallis test, with a confidence level of $95 \%$ and 0.05 significance level, indicated no significant difference in balance and gait scores in the Tinetticale between age groups in any of the two conducted evaluations. 
Table 4. Distribution of averages from the Kruskal-Wallis test between ages and points in the Tinetti Scale in the first and second evaluations, and the frequency of falls per age group. Niteróiand Rio de Janeiro, 2014.

\begin{tabular}{|c|c|c|c|c|c|}
\hline Balance in Gait & $n$ & $\%$ & Average & SD & $p$-value \\
\hline \multicolumn{6}{|l|}{ First Evaluation Age } \\
\hline $60-69$ & 9 & 20.93 & 21.11 & 5.41 & \\
\hline $70-79$ & 24 & 55.81 & 20.37 & 3.69 & 0.97 \\
\hline $80-89$ & 10 & 23.26 & 20 & 3.33 & \\
\hline Total & 43 & 100 & 20.49 & & \\
\hline Balance in Gait & $n$ & $\%$ & Average & SD & $p$-value \\
\hline \multicolumn{6}{|c|}{ Second Evaluation Age } \\
\hline $60-69$ & 9 & 20.93 & 22.66 & 4.18 & \\
\hline $70-79$ & 24 & 55.81 & 21.83 & 3.19 & 0.709 \\
\hline $80-89$ & 10 & 23.26 & 21.1 & 3.03 & \\
\hline Total & 43 & 100 & 21.86 & 3.19 & \\
\hline Accidental Falls & $n$ & $\%$ & Average & SD & $p$-value \\
\hline \multicolumn{6}{|l|}{ Age } \\
\hline $60-69$ & 7 & 26.92 & - & - & \\
\hline $70-79$ & 12 & 46.16 & - & - & 0.3398 \\
\hline $80-89$ & 7 & 26.92 & - & - & \\
\hline Total & 26 & 100 & & & \\
\hline
\end{tabular}

Caption: $n$ : frequency, \%: percentage, SD: Standard Deviation. Source: Data from the study.

Thus, the comparison of results from elderlies aged 60 to 69 years with those in other age groups, taking into account the age difference between participants, showed that the youngest elderly demonstrated fewer improvements in balance and gait in the two studied institutions in the two evaluations performed. Improvements in balance were observed in all age groups, suggesting that all elderlies, regardless of age, presented satisfactory responses to the implemented psychomotor activities.

The majority of elderlies in this study belonged to the age group of 70 - 79 years; therefore, the highest percentage of accidental falls occurred in this age range. However, when comparing the proportion of falls within each age group, it is evident that the elderlies who fell the most were in the age range of 60 to 69 years. It is noteworthy that the 70 - 79 years age group showed the lowest incidence of falls, with a $p$-value of 0.3398 points.

It was observed that the youngest elderlies began presenting balance deficits earlier than the older elderlies from the two studied institutions. The older elderlies responded well to the psychomotor exercises implemented on equal terms to the youngest elderlies. Thus, the importance for the elderlies, regardless of age, of beginning the practice of regular exercise is understood. There is evidence in the literature that exercise and physical activity positively influence the measurements of strength, balance, and functional performance, decreasing the risk of falls in the elderly [18].

The use of the Elderly Falls Diary indicated that 26 elderlies (60.47\%) experienced falls; of these, 18 (34.62\%) had only one fall. However, eight (18.60\%) reported recurrent falls; a total of 52 falls occurred. The distribution of falls by type was as follows: 33 (63.46\%) resulted from imbalance, 16 (30.76\%) from stumbling, and 3 (6.06\%) from sliding.

The distribution of falls by location was: 31 (59.62\%) in the streets and $7(13.46 \%)$ in other places such as buses, malls, and health institutions. Therefore, 38 (73.08\%) falls occurred in public places. Few studies in Brazil address the occurrence of falls in the public environment [19] [20]. Hence, there is a need for the implemen- 
tation of government and public health policies that prioritize improving functional capacity, balance, and prevention and treatment of functional declines associated with the aging process, in an effective way that also seeks to improve elderlies' accessibility to the urban environment.

\section{Conclusions}

Most of the study participants were females, which supports the fact that men seek medical care less than women do. This reinforces the need for public health policies not only geared toward the aging population but especially to the male population, because this is a worldwide phenomenon. In this study, the majority of falls occurred in the streets and public places. Few studies address the accessibility of elderlies to the urban environment.

The study data demonstrated the importance of training professionals involved in health care for the elderly, and the performance of studies to develop strategies that provide better balance and functional capacity in elderlies with mild cognitive impairment.

This study aimed to significantly contribute to achieving the inclusion and high performance of a multiprofessional team involved in health care for the elderly, by pledging government institutions to approach this population directly, providing them the means to transit safely in public places and satisfactorily practice their daily activities.

It was concluded that psychomotor activities are beneficial to elderlies, regardless of age, proving their effectiveness when stimulation combined with continued cognitive and psychomotor activities are carried out.

\section{References}

[1] Manfrim, A. and Schmidt, S.L. (2011) Diagnóstico diferencialdas demências. In: Freitas, E.V., et al., Eds., Tratado de geriatria e gerontologia, 3rd Edition, Guanabara Koogan, Rio de Janeiro, Chapter 13, 158-168.

[2] Canineu, P.R., Samara, A.B. and Stella, F. (2011) Transtorno Cognitivoleve. In: Freitas, E.V., et al., Eds., Tratado de geriatria e gerontologia, 3rd Edition, Guanabara Koogan, Rio de Janeiro, Vol. 14, 170-177.

[3] Rabelo, D.F. (2009) Comprometimento cognitivo leve em idosos: avaliação, fatores associados e possibilidades de intervenção. Revista Kairós Gerontologia, São Paulo (SP), 12, 65-79.

[4] Costa, M., Rocha, L. and Oliveira, S. (2012) Educação em saúde: Estratégia de promoção da qualidade de vida na terceira idade. Revista Lusófona de Educação, Lisboa, 22, 123-140. http://revistas.ulusofona.pt/index.php/rleducacao/article/viewFile/3285/2434

[5] Boushon, B., Nielsen, G., Quingley, P., et al. (2012) How to Guide: Reducing Patient Injuries from Falls. Institute for Healthcare Improvement, Cambridge, MA. www.ihi.org

[6] Ministério da Saúde (BR) (2013) Anexo 01: Protocolo prevenção de quedas, Protocolo integrante do Programa Nacional de Segurança do Paciente. Brasília (DF).

[7] Lourenço, T., Lenardt, M.H., Kletemberg, D.F., Seima, M.D., Tallmann, A.E.C. and Neu, D.K.M. (2012) Capacidade funcional no idoso longevo: Uma revisão integrativa. Revista Gaúcha de Enfermagem, 33, 176-185.

http://www.seer.ufrgs.br/index.php/RevistaGauchadeEnfermagem/article/view/20717/19509

[8] Freitas, R., Santos, S.S.C., Hammerschmidt, K.S.A., Silva, M.E. and Pelzer, M.T. (2011) Cuidado de enfermagem para prevenção de quedas em idosos: Proposta para ação. Rev Bras Enferm, 64, 478-485. http://www.scielo.br/pdf/reben/v64n3/v64n3a11.pdf

[9] Folstein, M.F., Folstein, S.E. and Mchugh, P.R. (1975) Mini-Mental State: A Practical Method for Grading the Cognitive State of Patients for the Clinician. Journal of Psychiatric Research, 12, 189-198. www.ncbi.nlm.nih.gov/pubmed/1202204

[10] Bertolucci, P.H., Bruck, S.M., Campacci, S.R. and Juliano, Y. (1994) The Mini-Mental State Examination in a General Population: Impact of Educational Status. Arquivos de Neuro-Psiquiatria, 52, 1-7 http://www.ncbi.nlm.nih.gov/pubmed/8002795

[11] Tinetti, M.E. (1986) Performance-Oriented Assessment of Mobility Problems in Elderly Patients. Journal of the American Geriatrics Society, 34, 119-126. http://dx.doi.org/10.1111/j.1532-5415.1986.tb05480.x

[12] Rosa Neto, F., Sakae, T.M. and Poeta, L.S. (2011) Validação dos parâmetros motores na terceira idade. Revista Brasileira de Ciência e Movimento, 19, 20-25.

[13] Universidade de São Paulo (2010) Hospital Universitário, Grupo de Prevenção de Queda, Diário de quedas do idoso. São Paulo. http://www.redehumanizasus.net/67010-grupo-de-prevencao-de-quedas-do-hospital-universitario-da-universidade-de-s ao-paulo 
[14] Neto, R., et al. (2009) Manual de Avaliação Motora para Terceira Idade. Artmed, Porto Alegre.

[15] Instituto Brasileiro de Geografia e Estatística (2010) Censo 2010: População do Brasil é de 190.732.694 pessoas.. http://censo2010.ibge.gov.br/pt/noticias-censo?view=noticias\&id=3\&pagina=3\&paginar=1\&quantidade=10\&busca=1.

[16] Brucki, S.M.D., Nitrini, R., Caramelli, P., Bertolucci, P.H.F. and Okamoto, I.H. (2003) Sugestões para o uso do miniexame do estado mental no Brasil. Arquivos de Neuro-Psiquiatria, 61, 777-781. http://www.scielo.br/scielo.php?script=sci_arttext\&pid=S0004-282X2003000500014\&lng=en http://dx.doi.org/10.1590/S0004-282X2003000500014

[17] Oliveira, G.C. (2002) Psicomotricidade: Educação e reeducação um enfoque psicopedagógico. 7th Edition, Vozes, Rio de Janeiro.

[18] Granacher, U., Gollhofer, A., Hortobágyi, T., Kressig, R.W. and Muehlbauer, T. (2013) The Importance of Trunk Muscle Strength for Balance, Functional Performance, and Fall Prevention in Seniors: A Systematic Review. Sports Med, 43, 627-641. http://link.springer.com/article/10.1007/s40279-013-0041-1

[19] Freire Jr., R.C., Arêas, G.P.T., Arêas, F.Z.S. and Barbosa, L.G. (2013) Estudo da acessibilidade de idosos ao centro da cidade de Caratinga, MG. Revista Brasileira de Geriatria e Gerontologia, 16, 541-558. http://www.scielo.br/scielo.php?script=sci_arttext\&pid=S1809-98232013000300012\&lng=en http://dx.doi.org/10.1590/S1809-98232013000300012

[20] Mendes, T.A. and Valsecchi, V.L.A. (2007) Armadilhas do espaço urbano. Einstein, São Paulo (SP), 5, 99-104. http://apps.einstein.br/revista/arquivos/PDF/388-Einstein5-2_Online_AO388_pg99-104.pdf 